\title{
Index to Volume 3
}

ABELS, H. Which groups act distally?, 167

Akcoglu, M. A. And Sucheston, L. A stochastic ergodic theorem for superadditive processes, 335

BAKER, K. A. Strong shift equivalence of $2 \times 2$ matrices of non-negative integers, 501

Barnsley, M. F., Geronimo, J. S. and Harrington, A. N. Geometry, electrostatic measure and orthogonal polynomials on Julia sets for polynomials, 509

Block, L., Coven, E., Mulvey, I. AND Nitecki, Z. Homoclinic and non-wandering points for maps of the circle, 521

BLOCK, L. AND HART, D. Stratification of the space of unimodal maps, 533

BOYLE, M. Lower entropy factors of sofic systems, 541

Bratteli, O. AND EVANS, D. E. Dynamical semigroups commuting with compact abelian actions, 187

BURNS, K. Hyperbolic behaviour of geodesic flows on manifolds with no focal points, 1

Collet, P. AND ECKman, J.-P. Positive Liapunov exponents and absolute continuity for maps of the interval, 13

Coven, E. See Block, L. et al.

EBERLEIN, P. Rigidity of lattices of non-positive curvature, 47

ECkman, J.-P. See Collet, P. And Eckman, J.-P.

Evans, D. E. See Bratteli, O. And Evans, D. E.

Geronimo, J. S. See Barnsley, M. F. et al.

GUILlemin, V. AND STERNBERG, S. On collective complete integrability according to the method of Thimm, 219

HALL, G. R. Bifurcation of an attracting invariant circle: a Denjoy attractor, 87

Harrington, A. N. See Barnsley, M. F. et al.

HART, D. See Block, L. AND HART, D.

HURLEY, M. Bifurcation and chain recurrence, 231

IRWIN, M. C. The orbit of a Hölder continuous path under a hyperbolic toral automorphism, 345

KIFER, Y. Characteristic exponents of dynamical systems in metric spaces, 119

LAMOTTE, A. Structure de certains produits semi directs, 559

LEVITT, G. Flots topologiquement transitifs sur les surfaces compactes sans bord: contrexemples à une conjecture de Katok, 241

LEwowicz, J. Persistence in expansive systems, 567

LJUBICH, M, Ju. Entropy properties of rational endomorphisms of the Riemann sphere, 351

MCCluskey, H. ANd MANning, A. Hausdorff dimension for horseshoes, 251

MAÑÉ, R. Errata to 'A proof of Pesin's formula', 159

manning, A. See McCluskey, H. and Manning, A.

MARKLEY, N. G. Topological minimal self-joinings, 579

Mulvey, I. See Block, L. et al.

NASU, M. Constant-to-one and onto global maps of homomorphisms between strongly connected graphs, 387

Nitecki, Z. See Block, L. et al. 
OsIKAwA, M. Flows associated with product type odometers, 601

Pansu, P. Croissance des boules et des géodésiques fermées dans les nilvariétés, 415

PIMSNER, M. V. Embedding some transformation group $C^{*}$-algebras into AF-algebras, 613

Pugh, C. C. And Robinson, C. The $C^{1}$ Closing Lemma, including Hamiltonians, 261

Robinson, C. See Pugh, C. C. and Robinson, C.

RosenblatT, J. AND Swanson, R. Immediate conditional hyperbolicity in dynamical systems, 627

SMILlie, J. Periodic points of surface homeomorphisms with zero entropy, 315

Sternberg, S. See Guillemin, V. And Sternberg, S.

STOWE, D. C. Real analytic actions of $S L(2, R)$ on a surface, 447

Sucheston, L. See Akcoglu, M. A. And Sucheston, L.

SUTHERLAND, C. E. On a construction of unitary cocycles and the representation theory of amenable groups, 129

SWanson, R. See Rosenblat, J. and Swanson, R.

ZILLER, W. Geometry of the Katok examples, 135 